Any critical appreciation of the volume must depend upon the type of reader for whom the work is intended. It is doubtful whether anyone outside the boundaries of technical education, including the youth employment service and industrial training officers, would have either the understanding or the patience to comb through the mass of information and statistics presented to ascertain just how or why a technical education should be beneficial to his son or daughter. In that respect, the present work differs markedly from a similar volume on technical education recently published abroad in that it includes no photographic illustrations to stimulate imagination or to lighten the heavy going of text and tables.

For those who are directly concerned with technjcal education, however, this publication is invaluable : as a summary of the present state of technical education ; as a mine of statistical information ; and as a fairly stated point of view on present problems and on proposed future development. On this last. named point, however, it is noteworthy that although five specialist co-authors were called in, these and the main author are all without exception principals of colleges. The outlook of the class-teacher, the governor and councillor, the education officer, the regional council secretary, the youth employment officer, and of the industrial training executive are thus perforce excluded, or stated at second hand. At first sight, it may seem regrettable that the idea of "partnerships in technical education" so eloquently extolled in Chapter 5-"Running through all are three essentials, administrative, industrial and academic, and all must be preserved in balance if satisfactory harmonious progress is to be made"could not have been given practical expression in the compilation of this most comprehensive work. No reader of this book, however, more especially Dr. Venables's colleagues in technical education, will fail to be impressed by the immense task of authorship undertaken by him; nor to be grateful that, for a very reasonable price, a handbook of presentday technical education can be placed upon one's desk for day-to-day reference-for the first time since the War.

This treatise can therefore be warmly recommended to teacher, administrator and industrial training officer alike. It should also, by the synthesis it alone provides, do a great deal to place technical education in the forefront of progress.

HUGH A. WARREN

\section{EMULSION POLYMERIZATION}

\section{Emulsion Polymerization}

By Frank A. Bovey, I. M. Kolthoff, A. I. Medalia and E. J. Meehan. (High Polymers: a Series of Monographs on the Chemistry, Physics and Technology of High Polymeric Substances-Vol. 9.) Pp. xii +445 . (New York : Interscience Publishers, Inc. ; London: Interscience Publishers, Ltd., 1955.) 12.50 dollars.

SINCE emulsion polymerization was first described $S$ some thirty years ago, it has attracted a great deal of attention, and it has been found that emulsion polymers may differ very significantly in properties from their counterparts made in other ways. Much of our present understanding of this process arose from the massive effort devoted in the United States during the Second World War to the development of a synthetic rubber industry. The authors of the book under review were intimately involved in the fundamental research programmes associated with that effort, and write from a broad background of knowledge of the polymer field.

The specific problems of emulsion polymerization cannot even be formulated without an understanding of the process of polymerization in simpler systems. The authors might well have assumed their readers to possess such knowledge, or left them to acquire it from other available sources. Instead, they have chosen to make the book essentially self-contained. Following an introductory chapter, the next three chapters outline a treatment of free-radical polymerization which for the most part is not restricted in its application to emulsions. Chapter 5 gives an account of the properties of soap solutions and their ability to solubilize organic liquids, and thus leads up to Chapter 6, which discusses in detail the kinetics of emulsion polymerization. Following a general chapter on inhibitors, the authors turn to copolymerization, and show how normal copolymerization may be modified when the reaction is carried out in emulsion. A chapter on experimental methods includes a brief review of molecular weight procedures, while the final two chapters give a rather full account of the various systems used for the production of the American synthetic rubber $G R-S$.

This is most interesting and very well-written book, and will be widely welcomed for its connected account of the problems of emulsion polymerization. Because of the plan adopted, the title scarcely does the book justice : it could fairly be described as a general text-book of polymerization, with special reference to the problems of emulsion polymerization. The general sections of the book are of the same high standard as the more specific, and can be confidently recommended as an excellent introduction to the subject. The book is indeed one which might well be put into the hands of students were it: not for its unfortunately high price.

G. GeE

\section{ELECTRICAL SUPPLY SYSTEMS IN THE UNITED STATES}

Electrical Transmission and Distribution

Edited by Bernhardt G. A. Skrotzki. (Electric Utility Library.) Pp. ix +448. (London: McGrawHill Publishing Company, Ltd., 1954.) 56s. 6d.

A ANY good books have been written on the subjects of the generation and mains transmission of electrical energy, but the equally important one of distribution is possibly less well covered. In this volume it is pleasing to find the subject dealt with fully and in considerable detail. Written in an informal style, the book deals exclusively with practice in the United States, but British engineers will find much to interest them therein on this account. The treatment is more descriptive and practical than purely theoretical, and is written for those on the supply side rather than from the point of view of the designer of equipment. An introductory chapter deals with elementary electrical theory so far as is needed for the subsequent treatment.

The major part of the work is devoted to distribution systems, starting with a chapter on 